\title{
Evaluation of wet troposphere path delays from atmospheric reanalyses and radiometers and their impact on the altimeter sea level
}

\author{
J.-F. Legeais, M. Ablain, and S. Thao \\ Collecte Localisation Satellites, Parc Technologique du canal, 8-10 rue Hermès, 31520 Ramonville Saint-Agne, France
}

Correspondence to: J.-F. Legeais (jlegeais@cls.fr)

Received: 26 March 2014 - Published in Ocean Sci. Discuss.: 23 June 2014

Revised: 27 August 2014 - Accepted: 26 September 2014 - Published: 10 November 2014

\begin{abstract}
The assessment of long-term errors in altimeter sea level measurements is essential for studies related to the mean sea level (MSL) evolution. One of the main contributors to the long-term sea level uncertainties is the correction of the altimeter range from the wet troposphere path delay, which is provided by onboard microwave radiometers for the main altimeter missions. The wet troposphere correction (WTC) derived from the operational European Centre for Medium-Range Weather Forecast (ECMWF) atmospheric model is usually used as a reference for comparison with the radiometer WTC. However, due to several improvements in the processing, this model is not homogenous over the altimetry period (from 1993 onwards), preventing the detection of errors in the radiometer WTC, especially in the first altimetry decade. In this study, we determine the quality of WTC provided by the operational ECMWF atmospheric model in comparison with the fields derived from the ERA-Interim (ECMWF) and the National Centers for Environmental Predictions/National Center for Atmospheric Research (NCEP/NCAR) reanalyses. Separating our analyses on several temporal and spatial scales, we demonstrate that ERA-Interim provides the best modeled WTC for the altimeter sea level at climate scales. This allows us to better evaluate the radiometer WTC errors, especially for the first altimetry decade (1993-2002), and thus to improve the altimeter MSL error budget. This work also demonstrates the relevance of the interactions between the "altimetry" and "atmosphere" communities, since the expertise of each is of benefit to the other.
\end{abstract}

\section{Introduction}

Since the early 1990 s, sea level has been monitored by several altimeter space missions. These measurements have become essential in the understanding of the impact of climate change on mean sea level (MSL) evolution at global and regional scales, particularly in the coastal areas of the world (Willis and Church, 2012). However, ensuring the long-term consistency and stability of altimeter measurements is challenging. The rate of change of the global MSL has been determined to be around $3.2 \mathrm{~mm} \mathrm{yr}^{-1}$, with an error close to $0.6 \mathrm{~mm} \mathrm{yr}^{-1}$ over the 1993-2012 period (Ablain et al., 2012). The main contributors to such an uncertainty are the orbit errors, the ageing of the altimeter instrument and the correction of the altimeter range path delay (PD) associated with the water vapor and cloud liquid water in the troposphere (Ablain et al., 2009; Couhert et al., 2014). The wet troposphere correction (WTC) used in the estimation of sea level is usually computed from onboard nadir-looking microwave radiometers, which are well adapted for monitoring the highly variable wet troposphere signals at a variety of spatial scales. However, the errors associated with this WTC may be the largest contributor to the uncertainty of the global MSL estimation. Indeed, the long-term stability of the global WTC is estimated to be at the level of $\pm 0.3 \mathrm{~mm} \mathrm{yr}^{-1}$ (Obligis et al., 2010; Ablain et al., 2009). At regional scales, the correction displays strong geographical variations with higher values in areas of strong evaporation such as the tropics, and the uncertainty on the WTC stability may reach $1.0 \mathrm{~mm} \mathrm{yr}^{-1}$ in these regions (Brown et al., 2010; Ablain et al., 2012).

The radiometer instrumental drift that potentially affects the long-term stability of the WTC may result from not 
only the components' ageing but also from internal temperature variations induced by maneuvers or when the instrument is turned off. Almost all radiometers onboard past or current altimetry missions have suffered instrumental drifts (18.7 GHz channel for the TOPEX MicroWave Radiometer/TMR, $23.8 \mathrm{GHz}$ channel for ERS-2/MWR, $36.5 \mathrm{GHz}$ channel for the Envisat/MWR, mainly $34 \mathrm{GHz}$ channels for the Jason-1 JMR and Jason-2 Advanced AMR). The detection of these instrumental drifts is critical for altimetry and MSL studies, especially as atmospheric water vapor is strongly correlated with interannual El Niño-Southern Oscillations (ENSOs), and in the meantime, its long-term evolution is affected by climate warming. These natural variations represent a limiting factor for an accurate calibration of the radiometer WTC. An instrumental drift could thus be wrongly interpreted as a geophysical trend or even the opposite. Thus, a careful radiometer calibration is required to accurately measure the global and regional trends of the sea level (Cazenave et al., 2010).

To reduce the risks of misinterpreting the observed drifts, different methods have been developed to detect, assess and correct these instrumental drifts. Examples include comparison with other radiometers and with other independent data sets (GPS, radio sounding, etc.) (Keihm et al., 2000; Niell et al., 2001; Zlotnicki and Desai, 2004). An illustration of this was the detection of the spurious drift of the early TOPEX TMR measurements ( $\mathrm{Fu}$ and Haines, 2012). The Jason-1 and Jason-2 radiometers (JMR and AMR, respectively) have benefited from an internal calibration thanks to the noise diode system (Brown et al., 2007), but the associated WTC is affected by spurious jumps (Brown et al., 2011). The long-term survey of the measured brightness temperatures over naturally stable cold or hot terrestrial targets has provided a reduction of the JMR drift from 3 to $0.1 \mathrm{~mm} \mathrm{yr}^{-1}$ (Brown et al., 2007). For Jason-2, a semiautonomous radiometer calibration system (ARCS) aims to remove the largest jumps of the AMR measurements before the production of geophysical data records. However, it was not designed for climate-oriented calibration (Brown et al., 2011). For Jason3 , planned to be launched in 2015 , a periodic cold-sky look has been proposed that can be achieved by pointing the radiometer antenna into open space. This should improve the stability of the associated WTC and significantly reduce the time required to perform a climate-quality calibration. Finally, the radiometer drift can also be detected by comparison with the WTC derived from meteorological numerical models. The instrumental WTC is preferred to the modeled correction since it provides a better estimation of the wet troposphere path delay with respect to precision, sensitivity and spatial sampling (Stum, 1994; Urban et al., 2001). However, the modeled corrections remain one of the few independent references to assess the long-term stability of the radiometer corrections. Usually, the operational model derived from ECMWF (European Centre for Medium-Range Weather Forecasts) (Molteni et al., 1996) is used to make these comparisons. Drift, jumps and maneuvers have already been highlighted on TOPEX, Jason-1, Jason-2 and Envisat onboard radiometers (Obligis et al., 2010). The quality of ECMWF operational WTC is not, however, homogenous over the altimetry period (from 1993 onwards). This is due to several processing evolutions which produce jumps or drift, preventing or reducing our ability to detect errors on radiometer WTC, especially in the first altimetry decade. Atmospheric reanalyses such as the ECMWF ERA-Interim (Dee et al., 2011) or that of the National Centers for Environmental Predictions/National Center for Atmospheric Research (NCEP/NCAR) (Kalnay et al., 1996) have been more uniformly processed than the operational model, thereby eliminating jumps due to changes to the processing strategy. The objective of this study is to better characterize the radiometer uncertainties by comparing the instrumental correction of the main altimeter missions over the entire altimeter era with all of these modeled WTC. This should determine whether one of these modeled corrections can be used as a reference to assess the radiometer WTC performances. The novelty of our approach is that the assessment of the modeled and instrumental WTC is performed through the analysis of altimeter sea level calculation and by separating several spatial and temporal scales well representative of climate signals.

A description of the method of comparison and the data used in this study is described in the next section. Then the quality of the modeled WTC is analyzed at short temporal scales. In the following section, the long-term stability of the WTC is discussed at global and regional scales. The ability to reproduce annual and interannual signals is then presented and a summary and discussion are provided.

\section{Data and methods}

\subsection{Models of wet troposphere corrections}

The ERA-Interim WTC is based on the ECMWF interim reanalyses (Dee et al., 2011) and it corresponds to the latest global atmospheric reanalysis of the model. The operational ECMWF WTC is produced by EUMETSAT using 3-D data from the ECMWF model to generate wet troposphere estimations. The NCEP/NCAR reanalysis (Kalnay et al., 1996) is provided by NOAA/OAR/ESRL PSD, Boulder, Colorado, USA, and is available from their website at http://www.esrl.noaa.gov/psd/. These three data sets are available as 4-times-daily global grids with a $0.75^{\circ} \times 0.75^{\circ}$ spatial resolution for ERA-Interim, an increasing resolution over the altimetry era from $0.5^{\circ} \times 0.5^{\circ}$ up to $0.12^{\circ} \times 0.12^{\circ}$ for the operational ECMWF model and $2.5^{\circ} \times 2.5^{\circ}$ for the NCEP/NCAR reanalysis.

\section{2 $\quad$ Altimeter data used}

The altimetry era (1993-2012) has been sampled by two time series derived from the TOPEX/Poseidon (TP), Jason-1 (J1) 
and Jason-2 (J2) missions, and also from the ERS-1 (E1), ERS-2 (E2) and Envisat (EN) missions. As each satellite platform has its own onboard radiometer with different spatial coverage and temporal resolution, both time series have been used for this study in order to better validate the results. The altimeter measurements used are the Archiving, Validation, Interpretation of Satellite Oceanographic (AVISO) data (AVISO, 2013). The radiometer WTC is generally directly derived from level-2 altimeter products, usually called geophysical data records (GDR). However in order to use the latest and best correction available, there are some exceptions. For Jason-1, we have applied the enhanced Jason-1 Microwave Radiometer (Brown, 2010) corrections containing better wet troposphere path delay corrections along with better land, rain and ice flagging for coastal regions than that found in the GDR-C release. For TOPEX, the radiometer WTC included in TP merged GDR products (M-GDR) has been corrected with a drift correction (Scharoo et al., 2004) and empirical correction of yaw maneuvers (TOPEX 2005 annual validation report, AVISO, 2006). For Jason-2, the correction is derived from the GDR-D release. Concerning ESA missions, for Envisat, we use a very recent correction (internal technical note: reprocessing of RA2-MWR v2.1b. CLSDOS-NT-13-114.), allowing for improvement in the small temporal scales $(<20$ days $)$ of sea level. For ERS-2, we use an updated correction derived from a neural algorithm (Obligis et al., 2006). For the ERS-1 mission, the correction of the ocean products (OPR, ERS equivalent of GDR product) is used. For all radiometer WTC, an editing criterion is used so that the values of the correction out of the range $[-0.50,0.0 \mathrm{~m}]$ are edited.

\subsection{Strategy and method of comparison}

In order to accurately compare WTC between models and radiometers, we interpolate the model's grids in space and time (by bilinear interpolation) on the satellite ground tracks. Note that we have used the already interpolated along-track values provided in the altimeter products for the WTC derived from the operational ECMWF model, whereas we have computed the WTC derived from the two atmospheric reanalyses. We have been able to check with some 3-D output fields of the operational ECMWF model that our computation algorithm is correct and does not contribute to any difference between the different modeled WTC. The comparison of along-track interpolated values reduces the effect of the spatiotemporal sampling of altimeters. Another main interest is to directly calculate the altimeter sea surface height ( $\mathrm{SSH}$ ) successively using WTC derived from models and radiometers. Through analysis of the differences between altimeter sea level estimations computed with different corrections, we are able to assess the quality of the WTC by evaluating the primary signals that are representative of climate scales.

The analyses are focused on the long-term evolution (trend over a period longer than 10 years) of the global and regional sea level, which is relevant for climate studies. Global and regional trend differences between models and radiometers are computed over the 20 years of the altimetry era (from 1993 onwards) applying the MSL calculation method described on the AVISO website (http://www.aviso.altimetry.fr/en/data/ products/ocean-indicators-products/mean-sea-level.html).

The biases between the different radiometers are removed when calculating the temporal evolution of the differences between altimeter sea levels corrected from different WTC over the altimetry era. These biases are precisely estimated thanks to the measurements from the verification phases when the satellites follow each other in close succession and the same atmosphere is measured by the onboard radiometers.

We also analyze interannual (signals between 2 and 5 years) and annual signals, which are of great interest in explaining the complex mechanisms of the ocean variability. Llovel et al. (2011) have shown that the interannual global MSL variations could be linked to land water storage oscillations, especially during ENSO events. A better description of these signals requires a very accurate calculation of the global MSL at interannual timescales, and thus it is fundamental to determine WTC errors at these temporal scales.

Finally, we also estimate the impact of WTC at shorter scales (lower than 10 days). These scales are indirectly linked with climate scales since high temporal frequency errors increase the formal error estimation of larger temporal signals previously described. The impact of using various models of WTC on the SSH performances is estimated by computing the variance of the SSH differences between ascending and descending tracks of each altimeter. Crossover points with time lags less than 10 days are selected so that, at each point of comparison, the altimeter is considered to measure nearidentical sea state at the same place. As the atmospheric temporal autocorrelation scale is relatively close to a few hours (Stum, 1998), this allows for a good estimation of the impact of this correction on the high-frequency part of the altimeter $\mathrm{SSH}$. Moreover, in order to keep the regions where the signal will be stronger, additional editing of the crossover points is performed, using only data with latitudes lower than $50^{\circ}$, bathymetry deeper than $-1000 \mathrm{~m}$ and regions of ocean variability lower than $400 \mathrm{~cm}^{2}$. This selection is performed only for the crossover points analysis in Sect. 3. In this study, the term "SSH performances" is used to assess to what extent altimeter sea levels are similar at the crossover points between ascending and descending tracks.

\section{High frequencies of the sea level}

\subsection{Global scale}

The impact of the modeled or radiometer WTC in the calculation of SSH for high-frequency signals (lower than 10 days) is quantified by plotting the temporal evolution of the SSH 

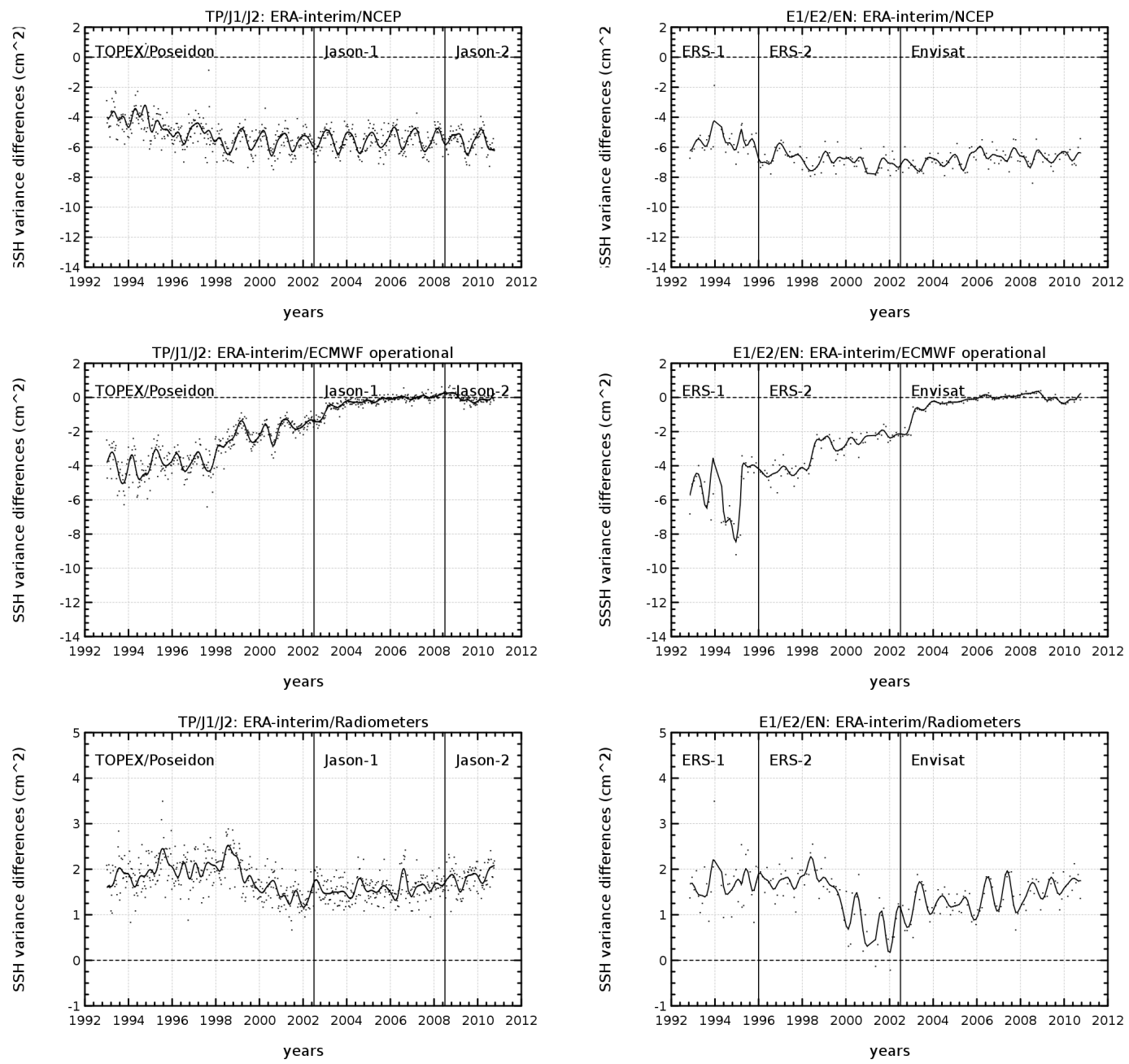

Figure 1. Temporal evolution of sea surface height (SSH) variance differences at crossovers (in $\mathrm{cm}^{2}$ ) using different wet troposphere corrections successively in the calculation of SSH: ERA-Interim and NCEP/NCAR reanalysis (top), ERA-Interim and ECMWF operational (middle), ERA-Interim and radiometer (bottom). Statistics have been computed with TOPEX/Jason-1/Jason-2 data on the left and ERS1/ERS-2/Envisat on the right without any selection of the data.

variance differences at crossovers (see Sect. 2) computed successively with different WTC in the estimation of SSH (Fig. 1). Compared with the use of the operational ECMWF model (middle panels of Fig. 1), the altimeter SSH performances are significantly improved with the ERA-Interim reanalysis. The improvement is greater over the first decade of the altimetry era, with a variance reduction of $6 \mathrm{~cm}^{2}$ before 1995 and close to $2 \mathrm{~cm}^{2}$ around 2002. Note that a strong deterioration is observed in 1994 (a relative $4 \mathrm{~cm}^{2}$ decrease) for ERS- 1 crossovers, which is not detected with the TP measurements in the same period. This most likely highlights an anomaly in the operational ECMWF WTC available in the ERS-1 products. Over the second decade, the improvement is lower than $2 \mathrm{~cm}^{2}$ and becomes insignificant from 2006 onwards (lower than $0.5 \mathrm{~cm}^{2}$ ), but no deterioration is measured with ERA-Interim. This result is not expected, since the operational ECMWF model has benefited from significant improvements, mainly associated with an increased spatial resolution, an improvement in the data assimilation process, and evolutions of the model (Andersson et al., 2005). Thus, the operational model should better solve the small spatial and temporal scales than its reanalysis. This smaller impact than expected could be related to coastal areas which are not included in these statistics (bathymetry deeper than $-1000 \mathrm{~m}$ ), but this remains to be investigated. Charts in the top panels of Fig. 1 indicate that the ERA-Interim reanalysis provides a significant improvement in the altimeter SSH performances compared with the NCEP/NCAR model (negative variance differences). The variance reduction remains relatively constant over the altimeter era, regardless of whether it is computed with the TP/J1/J2 time series $\left(5 \mathrm{~cm}^{2}\right)$ or with the E1/E2/EN measurements $\left(6 \mathrm{~cm}^{2}\right)$. Thanks to this gain in performance with the ERA-Interim WTC, the impact of using this reanalysis is now estimated by comparison with 

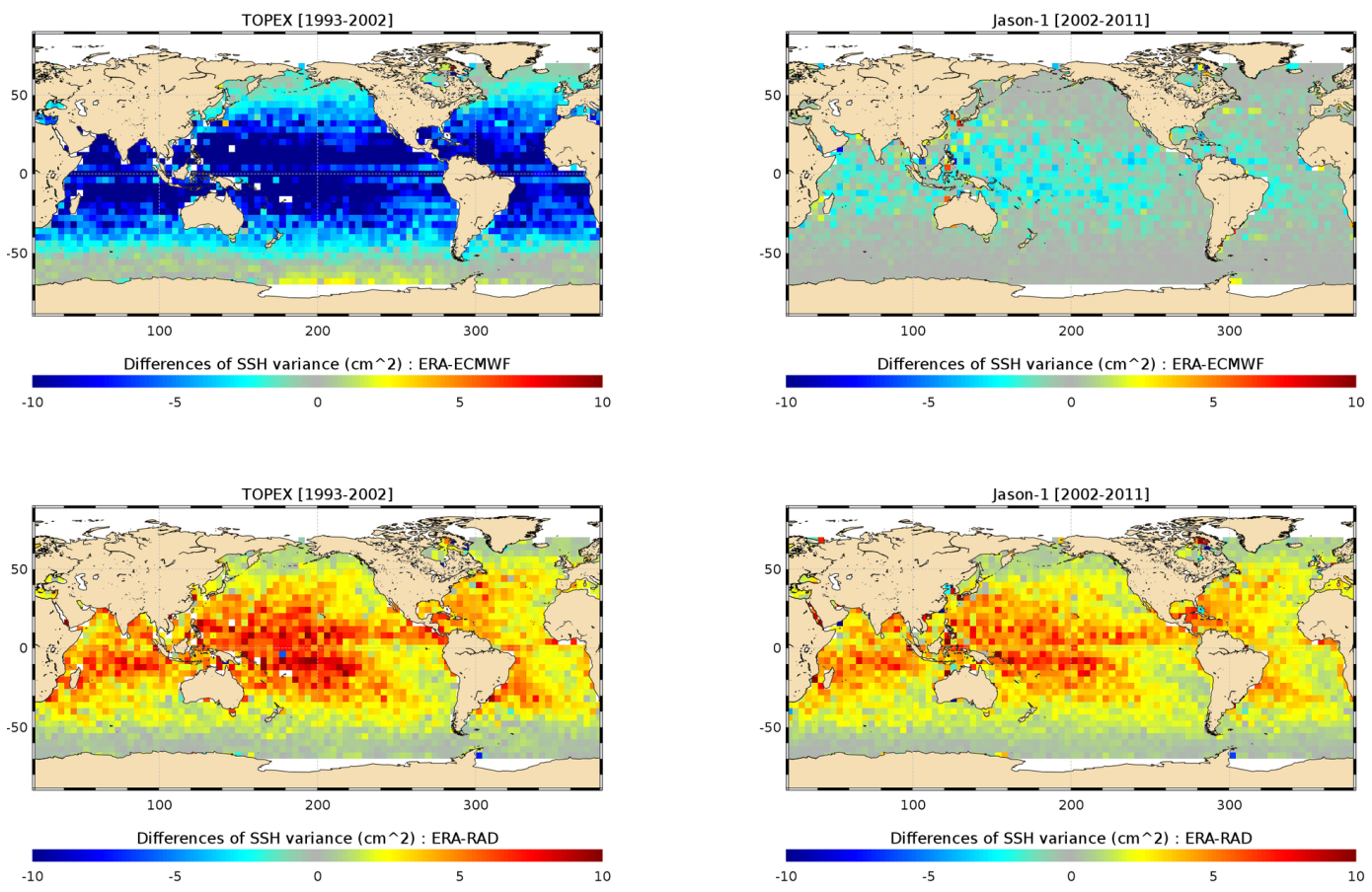

Figure 2. Map of SSH variance differences at crossovers (in $\mathrm{cm}^{2}$ ) using the ERA-Interim and radiometer wet troposphere corrections (bottom) and the ERA-Interim and ECMWF wet troposphere correction (top) successively in the calculation of SSH. Statistics have been computed over the first altimetry decade (from 1993 to 2002) using TOPEX data (left) and the second altimetry decade (from 2002 to 2011 ) using Jason-1 data (right).

radiometer WTC at crossovers. The bottom panels of Fig. 1 display the temporal evolutions of the variance differences and clearly indicate better performances of the radiometers (positive variance differences) at these timescales. The increase in variance is relatively constant over the 20 years of both altimeter time series (between 1 and $2 \mathrm{~cm}^{2}$ ).

\subsection{Regional scales}

Figure 2 displays the spatial distribution of the crossover $\mathrm{SSH}$ variance differences. The period of study is separated over the two decades of the altimetry era (1993-2002, 20022011) in order to take into account the evolution of the operational ECMWF model's quality. The better results obtained with ERA-Interim compared with the operational ECMWF model over the first decade are spatially homogeneously distributed between $50^{\circ} \mathrm{S}$ and $50^{\circ} \mathrm{N}$, with a variance reduction of $10 \mathrm{~cm}^{2}$ at low latitudes. This constitutes a drastic improvement in the SSH estimations. Over the second decade (upper right panel of Fig. 2), the SSH variance reduction obtained with the reanalysis is restricted to latitudes lower than $30^{\circ}$, where the wet troposphere physical content is higher, with differences less than $3 \mathrm{~cm}^{2}$. No impact is observed at these timescales at higher latitudes.

The bottom panels of Fig. 2 show the impact of using the ERA-Interim reanalysis WTC compared with the use of the radiometer WTC. The positive values indicate that the altimeter SSH performances are deteriorated with the model by a relatively homogeneous magnitude over the altimeter period. Slightly higher differences are observed in the western part of the Atlantic and Pacific oceans, with values up to $5 \mathrm{~cm}^{2}$ in this latter basin.

Thus, at short temporal scales and as expected, improved altimeter SSH performances are obtained with the use of microwave radiometers, demonstrating the importance of the availability of such instruments onboard satellite altimeters. However, the radiometer WTC performances are better characterized at small temporal scales with the ERA-Interim reanalysis since it provides significantly improved results compared with the use of the operational ECMWF model (notably over the first altimetry decade) and the NCEP/NCAR reanalysis (over the entire altimetry era). The quality assessment of the WTC at longer timescales will benefit from improved precision at shorter ones. Indeed, reduced highfrequency errors will decrease the formal error estimation of the signals at longer wavelengths such as the annual cycle or the trend. 

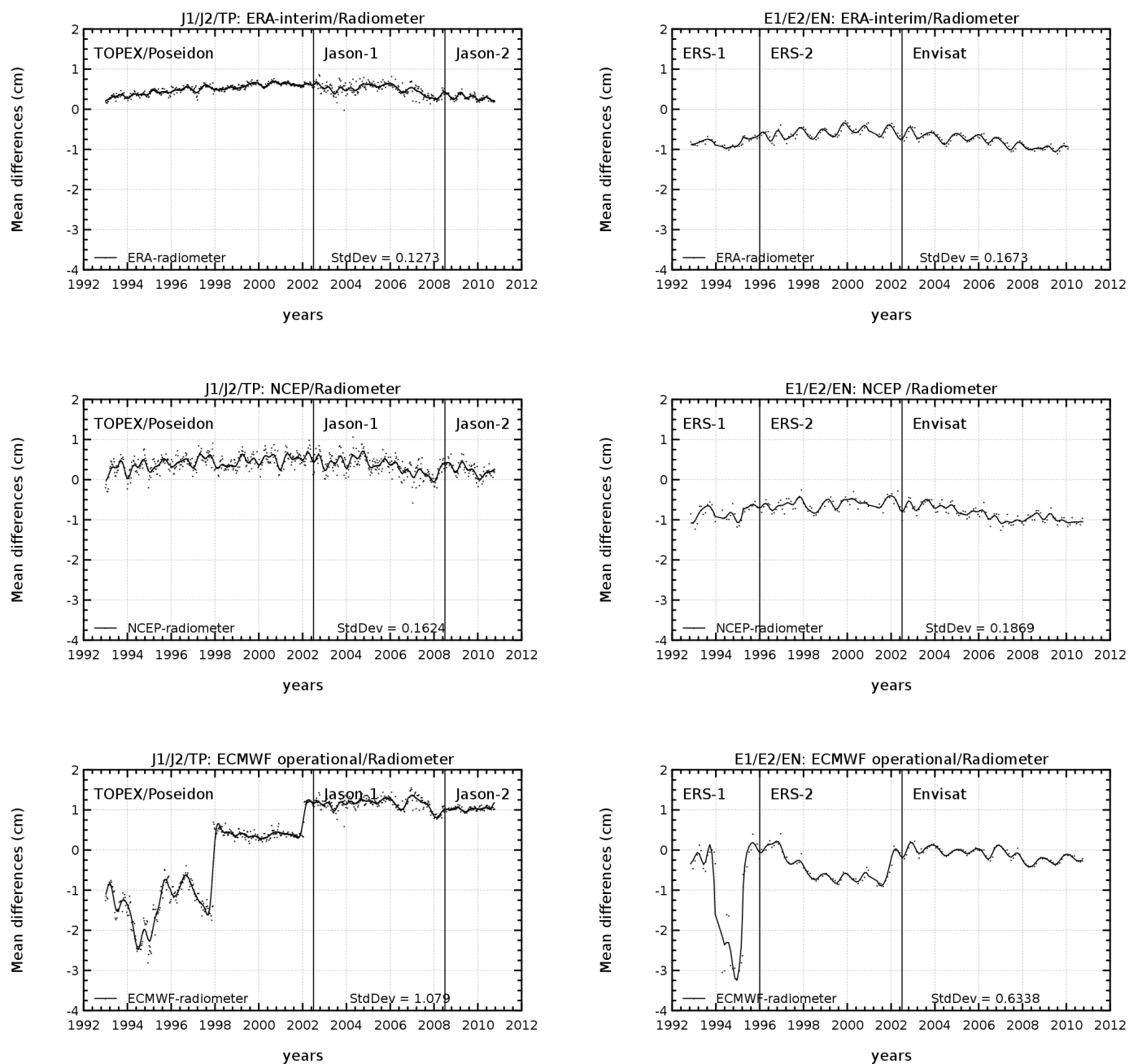

Figure 3. Temporal evolution of global mean differences between altimeter SSHs corrected from wet troposphere corrections computed with several models and the radiometers (in $\mathrm{cm}$ ): ERA-Interim reanalysis (top), NCEP/NCAR reanalysis (middle) and ECMWF operational (bottom). Statistics have been computed with TOPEX/Jason-1/Jason-2 data on the left and ERS-1/ERS-2/Envisat on the right without any geographical selection of the data. The biases between the radiometer measurements of the altimeter missions have been removed.

\section{The long-term stability of the altimeter sea level}

\subsection{Global mean sea level}

The impact of using the modeled WTC instead of the radiometer correction is now analyzed in terms of the global drift of the altimeter SSH anomalies. The suitability of reanalyses to characterize trends and the drift of the wet troposphere correction in particular has already been discussed (Bengtsson et al., 2004; Dessler and Davis, 2010; Thorne and Vose, 2010); those studies suggest a strong sensitivity to the computational methods and to the data assimilation (changes in the global observing system). Here, we want to determine whether a modeled WTC can be used to detect a drift of the radiometers and which model is the most adapted for such a detection.
Figure 3 presents the temporal evolution of differences between altimeter sea levels corrected from different WTC, where the biases between the different radiometers have been removed, as described in Sect. 2 . The differences between the operational ECMWF model and the radiometer correction (bottom panels) present a high variability (standard deviation of 1.1 and $0.6 \mathrm{~cm}$ for the TP/J1/J2 and E1/E2/EN time series, respectively) with some jumps as in $2002(1 \mathrm{~cm})$. This evolution is attributed to the upgrades of the operational model and illustrates that the stability of the operational model's outputs can not be guaranteed (Fernandes et al., 2014). Similar to the case of the ERS-1 anomaly observed in 1994 (see Sect. 3), we believe that the $2 \mathrm{~cm}$ jump observed in 1998 with TP data only is related to the update of the correction in the altimeter products. The variability of the global MSL differences is drastically reduced when the ERA-Interim (upper panels) and NCEP/NCAR (middle panels) reanalyses are compared 


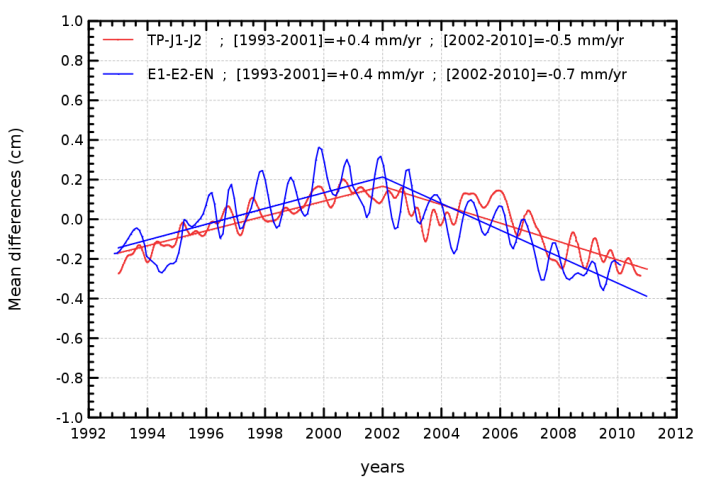

Figure 4. Temporal evolution of global mean differences between altimeter SSHs corrected from wet troposphere corrections computed with ERA-Interim and the radiometers (in $\mathrm{cm}$ ). Statistics are computed with TOPEX/Jason-1/Jason-2 data (in red) and ERS1/ERS-2/Envisat data (in blue) without any geographical selection. The drifts between ERA-Interim and radiometer WTC have been computed according to decades (1993-2001 and 2002-2010) for both time series and are indicated at the top.

with the instrumental correction since the reanalyzed time series are much more stable than the outputs of the operational model. A stronger annual signal is observed in the differences with ERS-1 and 2 and Envisat than with TOPEX and Jason-1 and 2, which is mainly associated with the difference of spatial coverage. The standard deviation of the differences is slightly smaller with ERA-Interim compared to the NCEP/NCAR reanalysis, regardless of the altimeter data used $(0.1 \mathrm{~cm}$ vs. $0.2 \mathrm{~cm}$ for the $\mathrm{TP} / \mathrm{J} 1 / \mathrm{J} 2$ time series). The ERA-Interim WTC has the closest long-term behavior to the radiometers, which suggests that the stability of the instrumental WTC can be analyzed in more detail by comparison with this reanalysis.

From thorough analysis of the temporal evolution of the differences between the modeled and the instrumental WTC, a "parabolic" signal is highlighted (Fig. 3, top panels) for the $\mathrm{TP} / \mathrm{J} 1 / \mathrm{J} 2$ time series as well as for the E1/E2/EN one. Similar evolution is depicted with the NCEP/NCAR reanalysis but not as significantly (middle panels). To better highlight this signal, the temporal evolution of the former difference is shown in Fig. 4 with a reduced range of the ordinate axis, with both altimeter time series and the associated trends computed separately for the two decades. The drift of the ERA-Interim reanalysis compared with the radiometer correction is of $+0.4 \mathrm{~mm} \mathrm{yr}^{-1}$ over the first period and -0.5 and $-0.7 \mathrm{~mm} \mathrm{yr}^{-1}$ over the second period with the TP/J1/J2 and E1/E2/EN time series, respectively. We would like to know whether this evolution is attributed to the radiometers or to the reanalyzed fields.

The answer to this is not obvious. On the one hand, as the two consecutive linear signals are similarly observed when using the two different radiometer time series, and as the onboard microwave radiometers are different and a priori independent, this suggests that the error could be related to the modeled WTC. On the other hand, as the consecutive linear signals are similarly detected with both ERA-Interim and NCEP/NCAR reanalyses, and as both of these reanalyses are a priori independent, this leads to the opposite conclusion: errors will be due to radiometers. Therefore, an immediate conclusion can not be made on the origin of the errors between radiometer and models at these timescales.

Furthermore, the hypothesis that radiometers are completely independent might be inappropriate. On the one hand, some similarities exist between the algorithms that restitute the WTC from the brightness temperatures, and, on the other hand, similar channels are exploited by the radiometers (as the $23.7 \mathrm{~Hz}$ ) to measure the wet troposphere content. Therefore, even if the instruments are independent, a correlated signal error could be introduced by these potential dependences. In the same way, the independence of ERA-Interim and NCEP reanalyses could also be questioned since a common data assimilation anomaly has been introduced in both reanalyses (Dee et al., 2011; Kalnay et al., 1996). Thus, the determination of the origin of these parabolic signals requires further investigations on the processing of radiometer WTC as well as on the data assimilation in models.

\subsection{Regional mean sea level}

As strong differences can be distinguished in the spatial distribution of the water vapor troposphere content $(30 \mathrm{~cm}$ path delay differences between low and high latitudes), the regional MSL trends may be significantly affected by the altimeter WTC. At high latitudes, the radiometer measurements are deteriorated in the ice-covered regions, which should explain major discrepancies with the modeled WTC. The impact of the modeled or radiometer WTC on the regional MSL is analyzed in terms of the spatial distribution of the sea level trend differences (Fig. 5), and we focus on low and midlatitudes.

Firstly, when comparing the operational ECMWF model with the radiometer correction, strong differences of several millimeters per year in absolute values are obtained over the first altimetry decade (middle left panel). Over the second period (middle right), the MSL trend differences reach almost $+1.0 \mathrm{~mm} \mathrm{yr}^{-1}$ in the equatorial Indian and Pacific oceans and they are relatively homogeneously distributed elsewhere, with an average of $-0.5 \mathrm{~mm} \mathrm{yr}^{-1}$. This confirms that the operational model is not adapted to assess the regional MSL trends, particularly with the first altimeter records. Secondly, the MSL trends obtained with the WTC derived from the NCEP/NCAR reanalysis and the radiometer (bottom panels) depict differences of more than $\pm 3.0 \mathrm{~mm} \mathrm{yr}^{-1}$, with a strong spatial variability at low and midlatitudes over the global altimeter period. Finally, the ERA-Interim WTC provides the smallest differences in regional altimeter MSL trends compared to those derived from the radiometer (Fig. 5, upper panels). The discrepancies are mainly distributed along the 

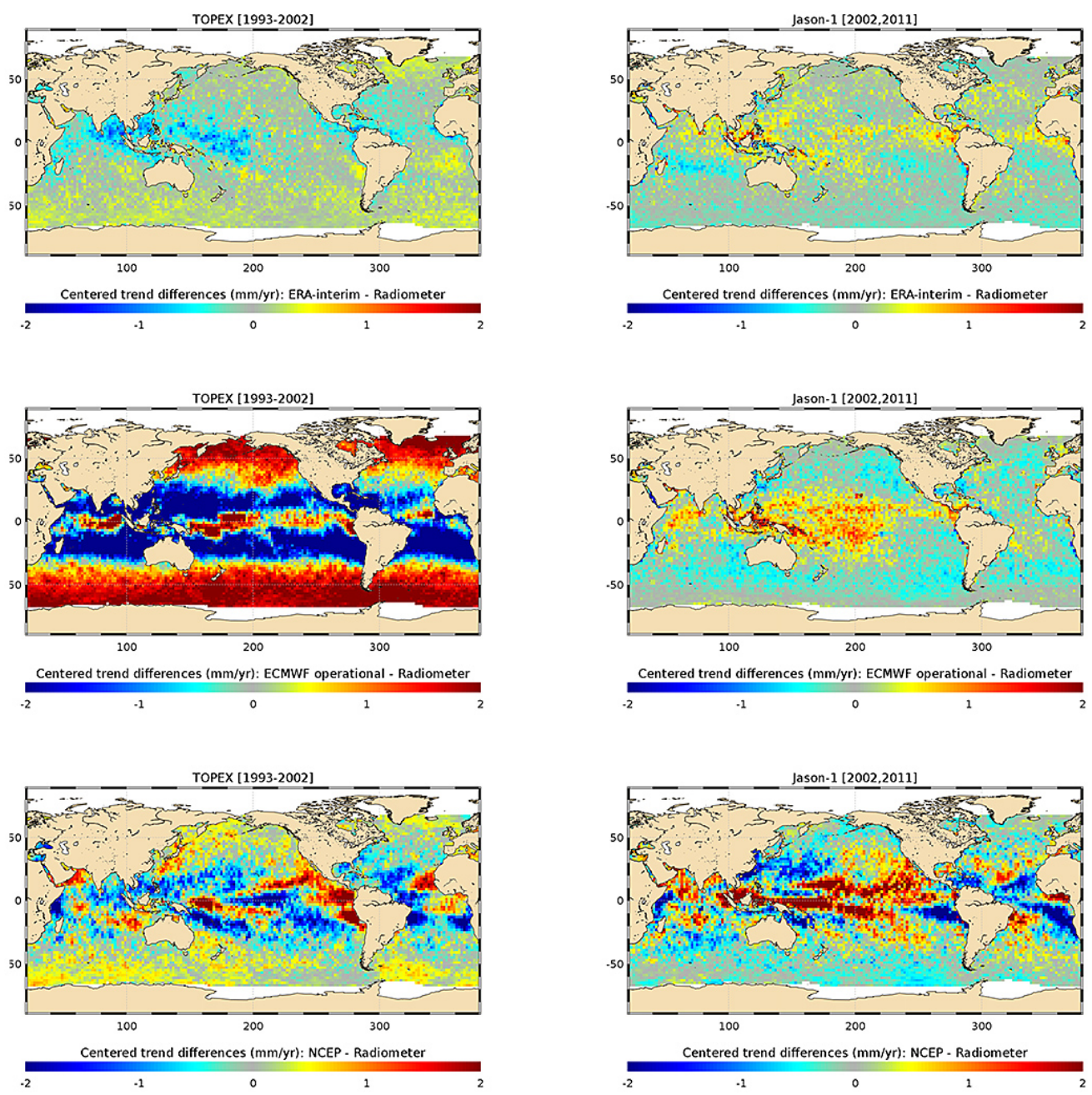

Figure 5. Map of the regional differences (centered on the mean, in $\mathrm{mm} \mathrm{yr}^{-1}$ ) between the trends of altimeter sea levels, successively corrected from modeled wet troposphere corrections and the radiometer corrections: ERA-Interim reanalysis (top), ECMWF operational (middle) and NCEP/NCAR reanalysis (bottom). Statistics have been computed over the first altimetry decade (from 1993 to 2002) with TOPEX data (left) and over the second altimetry decade (from 2002 to 2011) with Jason-1 data (right).

Equator and are in the range of $\pm 0.5 \mathrm{~mm} \mathrm{yr}^{-1}$ over both altimetry decades. No significant geographical bias is observed. However, smaller differences do not necessarily constitute an improvement. From looking at the spatial variability of the MSL trend differences, a more homogeneous distribution will suggest an improved quality. This spatial variability is reduced the most with the ERA-Interim reanalysis, especially for the first altimetry decade.

The performances of both reanalyses could not really be distinguished with regard to the impact on the global MSL trend (see previous section), but the regional approach reveals that the WTC derived from the ERA-Interim reanalysis is substantially better for assessing the radiometer's stability and thus the long-term evolution of the altimeter MSL. We can not determine whether the remaining MSL trend differences obtained when comparing the ERA-Interim reanalysis and the radiometer are attributed to the model or to the instrument. However, these comparisons contribute to better estimation of the errors in the radiometer at these timescales.

\section{Annual and interannual signals}

\subsection{Annual signals}

The annual signal of the atmospheric water vapor content (Nedoluha et al., 1996; Seele and Hartogh, 1999) directly affects the sea level estimation at this temporal scale through the altimeter range correction of the path delay. Over the first altimetry decade (TP measurements), the WTCs derived from both the ERA-Interim reanalysis and the operational ECMWF model provide altimeter SSH with amplitudes of the annual signal of about $3 \mathrm{~cm}$ (Fig. 6, top). This is very 
close to the one obtained with the radiometer correction (difference of less than $1 \mathrm{~mm}$ ). With the NCEP/NCAR reanalysis, this amplitude is significantly reduced, by more than $6 \mathrm{~mm}$, over this period. When considering Jason-1 records over the second altimetry decade (Fig. 6, bottom), the small difference previously observed between the operational ECMWF model, its reanalysis and the instrumental correction has now disappeared. A $3 \mathrm{~cm}$ amplitude of the annual signal is observed with all the associated corrections. The NCEP/NCAR reanalysis still provides significantly reduced amplitude compared with the others. These comparisons suggest that less confidence in the estimation of the annual signal derived should be attributed to this model. Similar results (not shown here) have been obtained with ESA missions (E1, E2, EN). Contrary to the high frequencies and long-term evolution previously discussed, the corrections derived from the ERA-Interim reanalysis and the operational ECMWF model have similar performances to all the instrumental corrections in order to estimate the annual signal of the global altimeter MSL.

\subsection{Regional annual signals}

When considering the global ocean, the impact of the WTC on the annual signal amplitude has been discussed in terms of altimeter SSH anomalies, but at regional scales, the impact will be less pronounced and it is more relevant to estimate it through the WTC itself. The bottom panels of Fig. 7 reveal significant differences of more than $1 \mathrm{~cm}$ between the annual signal amplitudes estimated with the WTC derived from the NCEP/NCAR reanalysis and from the radiometers, with a strong spatial variability at low and midlatitudes regardless of which period is considered. Secondly, the difference in amplitude obtained with the ECMWF operational model vs. the radiometer (Fig. 7 , middle panels) is large $(1 \mathrm{~cm})$ over the first altimetry decade and displays significant discrepancies until $50^{\circ}$ latitude. Improved results are observed over the second decade, with differences less than $5 \mathrm{~mm}$. Finally, the smallest differences and the most reduced spatial variability is detected with the ERA-Interim reanalysis over the first decade (top left panel of Fig. 7), with differences in the radiometer of less than $5 \mathrm{~mm}$, mainly zonally distributed at low and midlatitudes $\left(<30^{\circ}\right)$. The reanalysis provides slightly greater amplitude along the Equator and reduced at $10-30^{\circ}$ latitude. After the year 2000 , the results are similar to those obtained with the operational model but the consistency with the radiometer is slightly deteriorated with ERA-Interim in some regions. The ERA-Interim reanalysis is thus considered to have the best performances for the regional estimation of the annual signal of the WTC. This result is confirmed by the analysis of the phase of the annual signal (Fig. 8): very low phase differences are obtained with ERA-Interim reanalysis ( $<5$ days) over the whole altimetry period, whereas the ECMWF operational model and the NCEP/NCAR reanalysis provide stronger differences (up
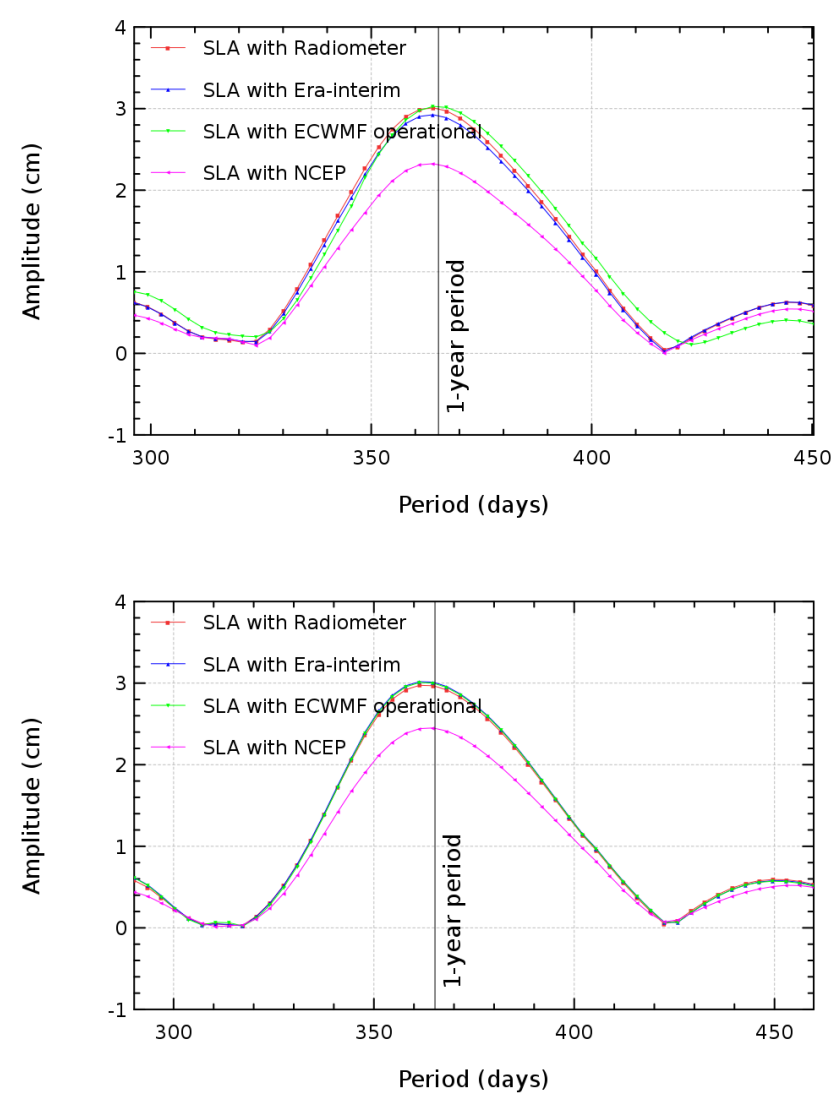

Figure 6. Amplitude of the annual signal (in $\mathrm{cm}$ ) of the global altimeter mean sea level derived with different wet troposphere corrections over the first (top, TP data) and the second (bottom, Jason-1 data) altimetry decade.

to 30 days). There is no evidence to attribute the remaining differences between ERA-Interim and the radiometer to the model or to the instrument. However, like for the MSL trends, these results contribute to better estimation of the radiometer errors for the estimation of the annual signals and thus refine the altimeter sea level budget error at these timescales.

\subsection{Interannual signals}

As explained previously, MSL variations at interannual timescales (2-5 years) are of main interest for climate studies. Thus, very good knowledge of the altimetry errors is required at these timescales, especially for the water vapor in the atmosphere, whose natural variations may be on the same order as that of the global MSL (a few millimeters) (Lagerloef et al., 1999; Cazenave et al., 2010). In both cases, for the MSL and wet troposphere contents, these interannual evolutions are strongly correlated with interannual ENSOs (Nerem et al., 1999).

To analyze the differences at these timescales, we compare time series of different WTC over a few years (Fig. 9). 

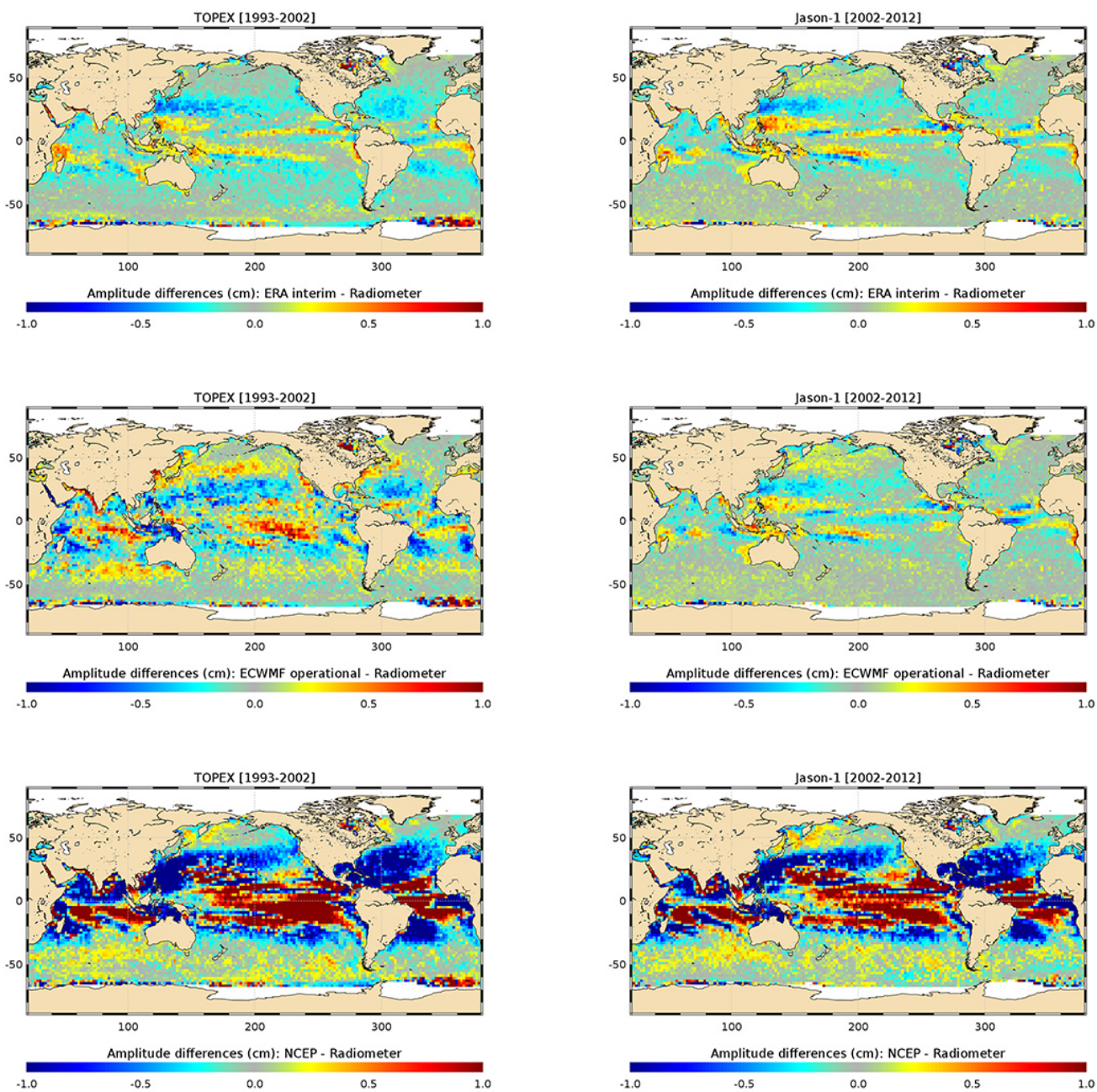

Figure 7. Regional differences in the annual signal's amplitude of the wet troposphere corrections (in cm) comparing each model (top: ERA-Interim; middle: operational ECMWF; bottom: NCEP/NCAR) with the radiometers over the first (left, TP data) and the second (right, Jason-1 data) altimetry decade. Contrary to other figures, we compare here the annual signal of the WTC itself.

Differences between the modeled and a radiometer WTC reveal distinct behaviors during the ENSO La Niña event of 2008. Except for the one derived from the operational ECMWF model, all corrections display a decrease in the wet troposphere path delay from the end of 2007 (dryer atmosphere) followed by an increase after mid-2008. A global difference of $3 \mathrm{~mm}$ is observed compared with the radiometer and the other modeled corrections. As it corresponds to the order of magnitude of the signals that we want to detect, this illustrates the difficulty in providing an appropriate reference to assess the performances of the microwave radiometers at the interannual timescales. This also highlights that the associated variations of the water cycle in the atmosphere are better reproduced with global reanalyses rather than with operational models. The estimation of the interannual signals could thus constitute an improvement target in these models.

\section{Discussion and conclusions}

The radar altimeter range needs to be corrected from the path delay associated with water vapor content of the troposphere. Onboard microwave radiometers are preferred to provide the associated WTC since they remain the most precise and sensitive solution for estimating the highly variable wet troposphere signals with enough spatial and temporal sampling. The aim of this study was to determine to which extent a modeled correction could be used as a reference to assess the quality of the instrumental WTC, which further enables MSL climate estimations. To do this, the instrumental corrections of main altimeter missions have been compared with modeled WTC over the whole altimeter era. This has been done after interpolating the grids of the models on the satellite ground tracks in order to accurately compare both types of corrections through the estimation of the altimeter SSH. This also allows for the separation of different wavelengths representative of climate scales. The WTC derived from the 

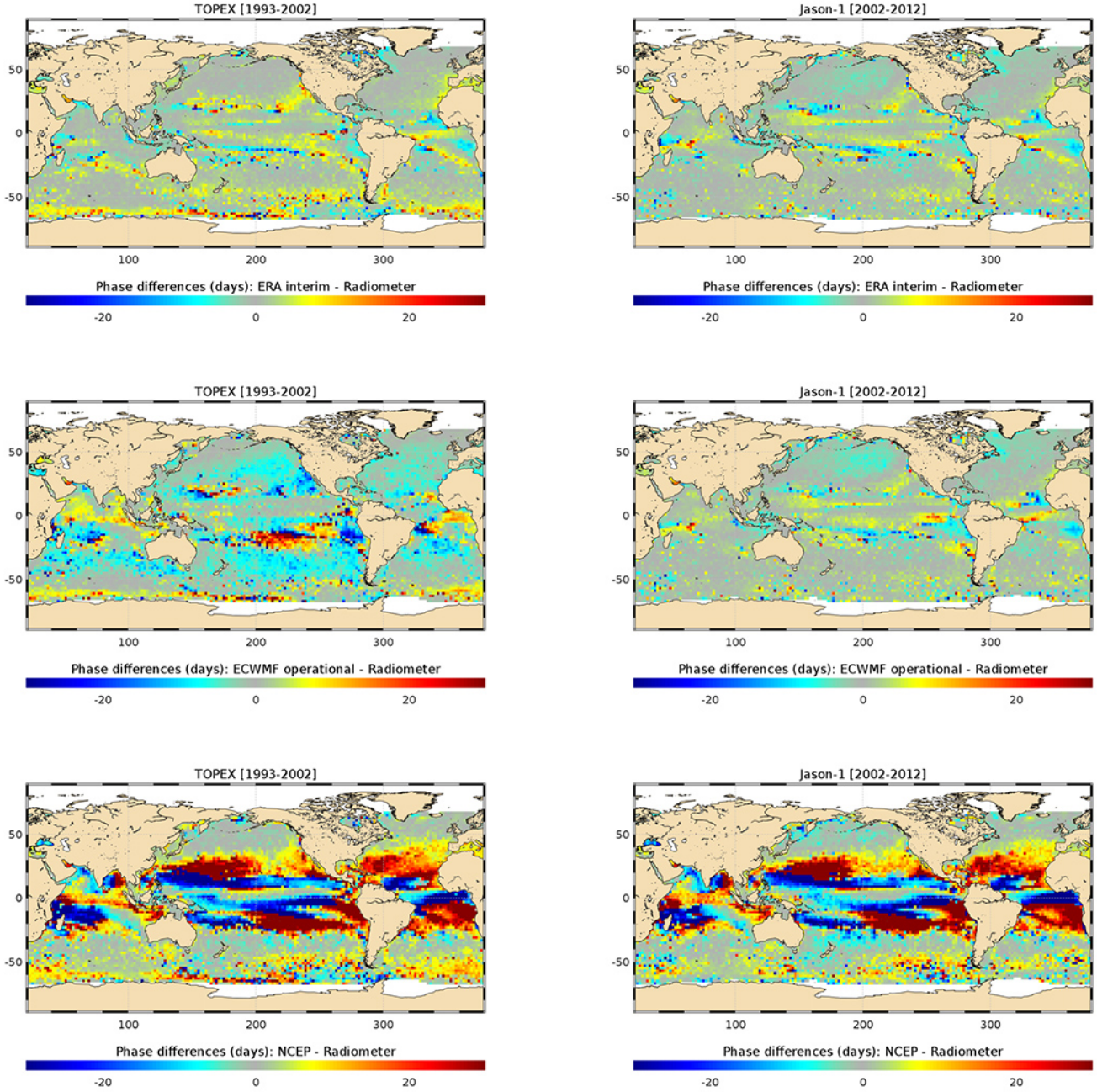

Figure 8. Regional differences in the annual signal's phase of the wet troposphere corrections (in days) comparing each model (top: ERAInterim; middle: operational ECMWF; bottom: NCEP/NCAR) with the radiometers over the first (left, TP data) and the second (right, Jason-1 data) altimetry decade. As in Fig. 8, we compare here the annual signal of the WTC itself.

ERA-Interim reanalysis appears to be the most adapted modeled reference to perform this quality assessment, particularly over the first altimetry decade: it provides a significant improvement in the altimeter SSH performances at small scales (less than 10 days) compared with the ECMWF operational modeled correction and it is substantially better for assessing the radiometer's stability and thus the long-term evolution of the altimeter MSL at regional scales. These results help to better characterize the altimeter sea level uncertainties associated with the wet troposphere path delay. This directly contributes to the refinement of the altimeter MSL error budget, which is fundamental for answering the user's requirements for climate applications.

However, some errors remain, particularly for the representation of the low-frequency variability of the water cycle in atmospheric reanalyses. The two linear evolutions observed over both altimetry decades when comparing the modeled WTC with the instrumental correction (Fig. 4) could be related to an anomaly detected in global atmospheric reanalyses such as ERA-Interim. Indeed, in the context of the so-called "rain assimilation", the greater the number of total column water vapor retrievals from SSM/I satellites, the greater the drying induced by the analysis increments. This results in the atmosphere being represented in ERA-Interim as more dry (wet) whenever an SSM/I satellite is introduced (withdrawn) in the rain assimilation process (P. Poli, personal communication, 2013). As several increases in the number of PWC (precipitable water content) retrievals occurred before 2001 and some decreases occurred from 2002 onwards, this could contribute to the observed evolution in Fig. 4.

This study demonstrates the benefit of using independent altimeter measurements to validate some fields of atmospheric reanalyses, such as the water vapor content of the wet troposphere. Similar work has also recently been performed for the pressure and wind fields derived from ERA-Interim 


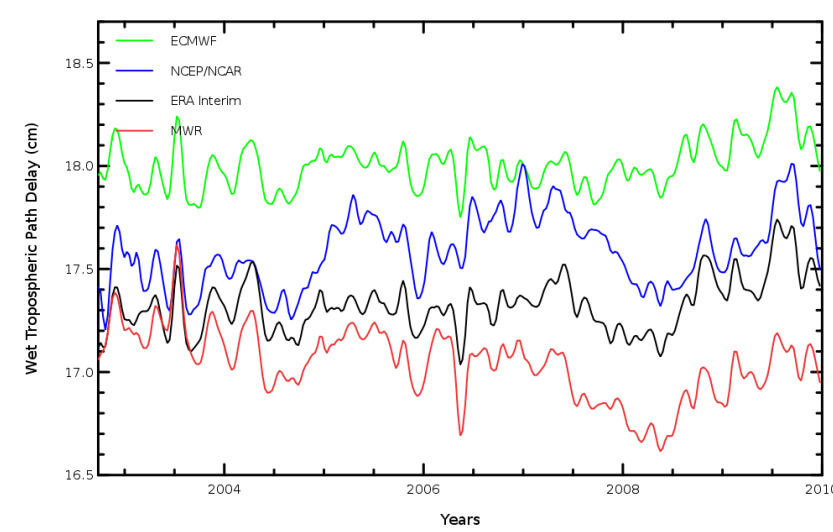

Figure 9. Time series of wet path delays (opposite of the wet troposphere correction, in $\mathrm{cm}$ ) derived from the Envisat MWR radiometer, the ERA-Interim and NCEP/NCAR reanalyses, and the operational ECMWF model. Data at latitudes lower than $66^{\circ}$ are selected and time series are 2-month-filtered and adjusted from annual and semiannual signals.

and other models (Carrère, 2014). In this way, interactions between the "altimetry" and "atmosphere" communities are relevant, since the expertise of each is of benefit to the other. Our approach will be adapted to assess the performances of other atmospheric reanalyses such as the new JRA-55 (Ebita et al., 2011) or the ERA-Clim/ERA-Sat reanalysis (Dee, 2012). The Japanese product, now available, is very promising, particularly because it may be free of the aforementioned problems related to the "rain assimilation".

Acknowledgements. This work has been performed within the framework of the ESA Climate Change Initiative (CCI) project. We are grateful for the contribution of Jérôme Benveniste from ESA and also for the fruitful discussions with Nicolas Picot from CNES within the SALP project. We thank Paul Poli from ECMWF for the elements of discussion he gave us on the ERA-Interim reanalysis.

Edited by: N. Wells

\section{References}

Ablain, M., Cazenave, A., Valladeau, G., and Guinehut, S.: A new assessment of the error budget of global mean sea level rate estimated by satellite altimetry over 1993-2008, Ocean Sci., 5, 193201, doi:10.5194/os-5-193-2009, 2009.

Ablain, M., Larnicol, G., Faugere, Y., Cazenave, A., Meyssignac, B., Picot, N., and Benveniste, J.: Error Characterization of Altimetry Measurements at Climate Scales. Proceedings of the 20 years of progress in radar altimetry symposium, Venice, available at: http://www.aviso.altimetry.fr/fileadmin/documents/ OSTST/2012/oral/02_friday_28/04_errors_uncertainties_I/03_ EU1_Ablain.pdf (last access: 20 March 2014), 2012.

Andersson, E., Bauer, P., Beljaars, A., Chevallier, F., Holm, E., Janiskova, M., Kallberg, P., Kelly, G., Lopez, P., Mcnally, A., Moreau, E., Simmons, A. J., Thépaut, J.-N., and Tompkins, A.
M.: Assimilation and Modeling of the Atmospheric Hydrological Cycle in the ECMWF Forecasting System, B. Am. Meteorol. Soc., 86, 387-402, doi:10.1175/BAMS-86-3-387, 2005.

AVISO: TOPEX/Poseidon validation activities, 13 years of T/P data (GDR-Ms), CLS.DOS/NT/05.240. SALP-RP-MA-EA-21315CLS, available at: www.aviso.altimetry.fr/fileadmin/documents/ calval/validation_report/TP/annual_report_tp_2005.pdf (last access: 20 March 2014), 2006.

AVISO: SSALTO/DUACS User Handbook: (M)SLA and (M)ADT Near-Real Time and Delayed Time Products, CLS-DOS-NT-06034, SALP-MU-P-EA-21065-CLS, 2013.

Bengtsson, L., Hagemann, S., and Hodges, K. I.: Can climate trends be calculated from reanalysis data?, J. Geophys. Res., 109, D11111, doi:10.1029/2004JD004536, 2004.

Brown, S.: A novel near-land radiometer wet path-delay retrieval algorithm: application to the Jason-2/OSTM advanced microwave radiometer, IEEE T. Geosci. Remote, 48, 1986-1992, doi:10.1109/TGRS.2009.2037220, 2010.

Brown, S., Desai, S., Wenwen, L., and Tanner, A. B.: On the long-term stability of microwave radiometers using noise diodes for calibration, IEEE T. Geosci. Remote, 45, 1908-1920, doi:10.1109/TGRS.2006.888098, 2007.

Brown, S., Desai, S., and Sibthorpe, A.: Error structures in the altimetry data from the Wet Tropospheric Path Delay correction, in: Proceedings of the OSTST Meeting, Lisbon, available at: http://www.aviso.altimetry.fr/fileadmin/ documents/OSTST/2010/oral/19_Tuesday/Brown.pdf (last access: 20 March 2014), 2010.

Brown, S., Desai, S., and Sibthorpe, A.: Improvements to the radiometer processing for GDR-D, in: Proceedings of the OSTST meeting, San Diego CA, available at: http://www.aviso.altimetry.fr/fileadmin/documents/OSTST/ 2011/oral/02_Thursday/Splinter5IP/04_Brown.pdf (last access: 20 March 2014), 2011.

Carrère, L.: Improvement of DAC for climate and mesoscale studies using the ERA-Interim dataset, in preparation, 2014.

Cazenave, A., Chambers, D. P., Cipollini, P., Fu, L.-L., Hurell, J. W., Merrifield, M., Nerem, R. S., Plag, H. P., Shum, C. K., and Willis, J.: The challenge for measuring sea level rise and regional and global trends, in: Proceedings of OceanObs'09: Sustained Ocean Observations and Information for Society, edited by: Hall, J., Harrison, D. E., and Stammer, D., Vol. 1, European Space Agency, Noordwijk, the Netherlands, 135-152, (ESA Special Publication WPP-306), available at: http://www.oceanobs09. net/proceedings/pp/2A3-Cazenave-OceanObs09.pp.11.pdf (last access: 3 July 2014), 2010.

Couhert, A., Cerri, L., Legeais, J.-F., Ablain, M., Zelensky, N., Haines, B., Lemoine, F., Bertiger, W., Desai, S., and Otten, M.: Towards the $1 \mathrm{~mm} / \mathrm{y}$ stability of the radial orbit error at regional scales, Adv. Space Res., online first, doi:10.1016/j.asr.2014.06.041, 2014.

Dee, D. P.: The forefront of climate monitoring, International innovation, available at: http://www.era-clim.eu/news/p27-29_ERA_ Clim_LowRes.pdf (last access: 20 March 2014), 2012.

Dee, D. P., Uppala, S. M., Simmons, A. J., Berrisford, P., Poli, P., Kobayashi, S., Andrae, U., Balmaseda, M. A., Balsamo, G., Bauer, P., Bechtold, P., Beljaars, A. C. M., van de Berg, L., Bidlot, J., Bormann, N., Delsol, C., Dragani, R., Fuentes, M., Geer, A. J., , Haimberger, L., Healy, S. B., Hersbach, H., Holm, E. V., 
Isaksen, L., Kallberg, P., Kohler, M., Matricardi, M., McNally, A. P., Monge-Sanz, B. M., Morcrette, J.-J., Park, B.-K., Peubey, C., de Rosnay, P., Tavolato, C., Thépaut, J.-N., and Vitart, F.: The ERA-Interim reanalysis: configuration and performance of the data assimilation system, Q. J. Roy. Meteor. Soc., 137, 553-597, doi:10.1002/qj.828, 2011

Dessler, A. E. and Davis, S. M.: Trends in tropospheric humidity from reanalysis systems, J. Geophys. Res., 115, D19127, doi:10.1029/2010JD014192, 2010.

Ebita, A., Kobayashi, S., Ota, Y., Moriya, M., Kumabe, R., Onogi, K., Harada, Y., Yasui S., Miyaoka, K., Takahashi, K., Kamahori, H., Kobayashi, C., Endo, H, Soma, M., Oikawa, Y., and Ishimizu, T.: The Japanese 55-year Reanalysis "JRA-55": An interim report, SOLA, 7, 149-152, doi:10.2151/sola.2011038, 2011

Fernandes, M. J., Lazaro, C., Nunes, A. L., and Scharroo, R.: Atmospheric Corrections for Altimetry Studies over Inland Water, Remote Sens., 6, 4952-4997, 2014.

$\mathrm{Fu}$, L.-L. and Haines, B. J.: The challenges in long-term altimetry calibration for addressing the problem of global sea level change, Adv. Space Res., 51, 1284-1300, doi:10.1016/j.asr.2012.06.005, 2012.

Kalnay, E., Kanamitsu, M., Kistler, R., Collins, W., Deaven, D., Gandin, L., Iredell, M., Saha, S., White, G., Woollen, J., Zhu, Y., Leetmaa, A., Reynolds, R., Chelliah, M., Ebisuzaki, W., Higgins, W., Janowiak, J., Mo, K. C., Ropelewski, C., Wang, J., Jenne, R., and Joseph, D.: The NCEP/NCAR 40-year reanalysis project, B. Am. Meteorol. Soc., 77, 437-470, doi:10.1175/15200477(1996)077<0437:TNYRP>2.0.CO;2, 1996.

Keihm, S., Zlotnicki, J. V., and Ruf, C. S.: TOPEX microwave radiometer performance evaluation, IEEE T. Geosci. Remote, 38, 1379-1386, 2000.

Lagerloef, G. S. E., Mitchum, G. T., Lukas, R. B., and Niiler, P. P.: Tropical Pacific near-surface currents estimated from altimeter, wind, and drifter data, J. Geophys. Res., 104, 23313-23326, doi:10.1029/1999JC900197, 1999.

Llovel, W., Becker, M., Cazenave, A., Jevrejeva, S., Alkama, R., Decharme, B., Douville, H., Ablain, M., and Beckley, B.: Terrestrial waters and sea level variations on interannual time scale, Global Planet. Change, 75, 76-82, doi:10.1016/j.gloplacha.2010.10.008, 2011.

Molteni, F., Buizza, R., Palmer, T. N., and Petroliagis, T.: The ECMWF ensemble prediction system: methodology and validation, Q. J. Roy. Meteor. Soc., 122, 73-119, doi:10.1002/qj.49712252905, 1996.

Nedoluha, G. E., Bevilacqua, R. M., Gomez, R. M., Waltman, W. B., Hicks, B. C., Thacker, D. L., and Matthews, W. A.: Measurements of water vapor in the middle atmosphere and implications for mesospheric transport, J. Geophys. Res., 101, 21183-21193, doi:10.1029/96JD01741, 1996.

Nerem, R. S., Chambers, D. P., Leuliette, E. W., Mitchum, G. T., and Giese, B. S.: Variations in global mean sea level associated with the 1997-1998 ENSO event: implications for measuring long term sea level change, Geophys. Res. Lett., 26, 3005-3008, 1999.
Niell, A. E., Coster, A. J., Solheim, F. S., Mendes, V. B., Toor, P. C., Langley, R. B., and Upham, C. A.: Comparison of Measurements of Atmospheric Wet Delay by Radiosonde, Water Vapor Radiometer, GPS, and VLBI, J. Atmos. Ocean. Tech., 18, 830-850, 2001.

Obligis, E., Eymard, L., Tran, N., Labroue, S., and Femenias, P.: First threeyears of the microwave radiometer aboard ENVISAT: in-flight calibration, processing, and validation of the geophysical products, J. Atmos. Ocean. Tech., 23, 802-814, 2006.

Obligis, E., Eymard, L., Ablain, M., Picard, B., Legeais, J.F., Faugère, Y., and Picot, N.: The wet tropospheric correction for altimetry missions: a Mean Sea Level issue, in: Proceedings of the OSTST meeting, Lisbon, available at: http://www.aviso.altimetry.fr/fileadmin/documents/ OSTST/2010/oral/19_Tuesday/OBLIGIS.pdf (last access: 20 March 2014), 2010.

Scharroo, R., Lillibridge, J., and Smith, W. H. F.: Cross-calibration and long-term monitoring of the microwave radiometers of ERS, Topex, GFO, Jason-1 and Envisat, Mar. Geod., 97, 279-297, doi:10.1080/01490410490465265, 2004.

Seele, C. and Hartogh, P.: Water vapor of the polar middle atmosphere: annual variation and summer mesosphere Conditions as observed by ground-based microwave spectroscopy, Geophys. Res. Lett., 26, 1517-1520, doi:10.1029/1999GL900315, 1999.

Stum, J.: A comparison between TOPEX microwave radiometer, ERS 1 microwave radiometer, and European Centre for Medium-Range Weather Forecasting derived wet tropospheric corrections, J. Geophys. Res., 99, 24927-24939, doi:10.1029/94JC01104, 1994.

Stum, J.: A comparison of the brightness temperatures and water vapor path delays measured by the TOPEX, ERS-1, and ERS-2 Microwave Radiometers, J. Atmos. Ocean. Tech., 15, 987-994, 1998.

Thorne, P. W. and Vose, R. S.: Reanalyses Suitable for Characterizing Long-Term Trends, B. Am. Meteorol. Soc., 91, 353-361, doi:10.1175/2009BAMS2858.1, 2010.

Urban, T. J., Pekker, T., Tapley, B. D., Kruizinga, G. L., and Shum, C. K.: A multiyear intercomparison of wet troposphere corrections from TOPEX/Poseidon, ERS-1 and ERS-2 microwave radiometers and the European centre for medium-range weather forecasts model, J. Geophys. Res.-Oceans, 106, 1965719669, doi:10.1029/2001JC000486, 2001.

Willis, J. K. and Church, J. A.: Regional sea-level projection, Perspect. Sci., 336, 550-551, 2012.

Zlotnicki, V. and Desai, S. D.: Assessment of Jason Microwave Radiometer's Measurement of Wet Tropspheric Path Delay using Comparisons with SSM/I and TMI, Mar. Geod., 27, 241-253, 2004. 